\title{
RUANG HAUSDORFF KOMPAK
}

\author{
Putri Aprilla Suri, Mariatul Kiftiah, Yundari
}

\begin{abstract}
INTISARI
Pada ruang topologi terdapat beberapa sifat, salah satunya adalah sifat kekompakan. Kekompakan dalam ruang topologi didefinisikan dengan terdapatnya berhingga koleksi himpunan terbuka yang dapat menutupi himpunan ruang topologi tersebut. Selain itu dalam ruang topologi juga dikenal dengan aksioma pemisahan yang membahas bagaimana titik atau himpunan di ruang topologi dapat dipisahkan satu sama lain. Terdapat beberapa ruang di dalam aksioma pemisahan yaitu, ruang- $T_{1}$ atau ruang Fréchet, ruang- $T_{2}$ atau ruang Hausdorff, ruang- $T_{3}$, dan ruang- $T_{4}$. Lebih lanjut terdapat juga ruang regular dan ruang normal yang secara berturut-turut adalah ruang- $T_{3}$ dan ruang- $T_{4}$ yang juga merupakan ruang- $T_{1}$. Suatu ruang Hausdorff belum tentu merupakan ruang regular maupun ruang normal, namun apabila suatu ruang Hausdorff yang dilengkapi dengan sifat kekompakan pasti merupakan ruang regular sekaligus ruang normal.
\end{abstract}

Kata kunci: ruang topologi, aksioma pemisahan, ruang Hausdorff, kekompakan

\section{PENDAHULUAN}

Ruang topologi dapat didefinisikan sebagai suatu himpunan titik-titik beserta hubungan persekitaran antar titik-titik tersebut [1]. Dalam ruang topologi dikenal sifat kekompakan. Istilah kompak diperkenalkan oleh Maurice Fréchet pada tahun 1904. Perhatikan bahwa definisi himpunan kompak dalam $\mathbb{R}$ adalah himpunan yang tertutup dan terbatas, namun di ruang topologi biasa himpunan kompak tidak sesederhana itu untuk dideskripsikan [2]. Dalam Adams dan Franzosa, definisi kekompakan diberikan oleh Pavel Alexandrov dan Pavel Urysohn sebagai adanya keberadaan koleksi himpunan terbuka yang banyaknya hingga yang dapat menutupi himpunan ruang topologi.

Lebih lanjut, dalam ruang topologi juga dikenal aksioma pemisahan yang merupakan batasanbatasan yang diciptakan saat seseorang hendak membuat ruang topologi, aksioma pemisahan ini mengandalkan distribusi himpunan terbuka di ruang topologi tersebut [3]. Terdapat beberapa ruang di dalam aksioma pemisahan yaitu, ruang- $T_{1}$ atau ruang Fréchet, ruang- $T_{2}$ atau ruang Hausdorff, ruang$T_{3}$, dan ruang- $T_{4}$. Selain itu terdapat juga ruang regular dan ruang normal yang secara berturut-turut adalah ruang- $T_{3}$ dan ruang- $T_{4}$ yang juga merupakan ruang- $T_{1}$. Suatu ruang normal pastilah ruang regular, ruang regular pastilah merupakan ruang Hausdorff, dan ruang Hausdorff pastilah ruang Frechet, namun tidak berlaku sebaliknya [4]. Akan tetapi jika suatu ruang Hausdorff yang dilengkapi dengan sifat kekompakan maka ruang Hausdorff kompak ini merupakan ruang regular dan juga ruang normal. Oleh karena itu, penelitian ini bertujuan untuk mengkaji karakteristik dan hubungan ruang Hausdorff kompak dengan ruang lainnnya pada aksioma pemisahan dilihat dari teorema yang berhubungan dengan ruang Hausdorff kompak.

Suatu ruang topologi $X$ dikatakan ruang Hausdorff kompak jika untuk setiap pasang $a, b \in X$ dengan $a \neq b$, terdapat himpunan terbuka saling asing yang memuat $a$ dan $b$ secara terpisah dan setiap liput terbuka $X$ memiliki liput bagian yang banyaknya berhingga [5]. Untuk selanjutnya dalam penelitian ini akan dibuktikan bahwa $X$ merupakan ruang regular dan ruang normal. Selain itu akan 
ditunjukkan pula suatu himpunan $K \subseteq X$ dikatakan kompak jika dan hanya jika $K$ tertutup dan terbatas.

\section{AKSIOMA PEMISAHAN}

Aksioma pemisahan merupakan aksioma yang membahas bagaimana titik atau himpunan di ruang topologi dapat dipisahkan satu sama lain. Berikut akan dijabarkan beberapa ruang dalam aksioma pemisahan.

Definisi 1. [6] Misalkan $X$ merupakan ruang topologi

1. Ruang topologi $X$ dikatakan ruang- $T_{1}$ atau ruang Fréchet jika untuk sebarang titik $a, b \in X$ dengan $a \neq b$ terdapat himpunan terbuka $U, V \subset X$ sedemikian hingga $a \in U, b \notin U$ dan $b \in V, a \notin V$

2. Ruang topologi $X$ dikatakan ruang- $T_{2}$ atau ruang Hausdorff jika untuk sebarang $a, b \in X$ dengan $a \neq b$ terdapat himpunan terbuka saling asing $U, V \subset X$ sedemikian hingga $a \in U, b \in V$.

3. Ruang topologi $X$ dikatakan ruang- $T_{3}$ jika untuk setiap $p \in X$ dan himpunan tertutup $K \subset X$ dengan $p \notin K$ terdapat dua himpunan terbuka $U, V \subset X$ sedemikian hingga $U \cap V=\emptyset, K \subset U$ dan $p \in V$.

4. Suatu ruang topologi $X$ dikatakan ruang- $T_{4}$ jika untuk setiap dua himpunan tertutup $A, B \subset X$ dengan $A \cap B=\varnothing$ terdapat dua himpunan terbuka $U$ dan $V$ sedemikian hingga $U \cap V=\varnothing, A \subset U$, dan $B \subset V$.

Berikut diberikan ilustrasi dari keempat ruang pada aksioma pemisahan.
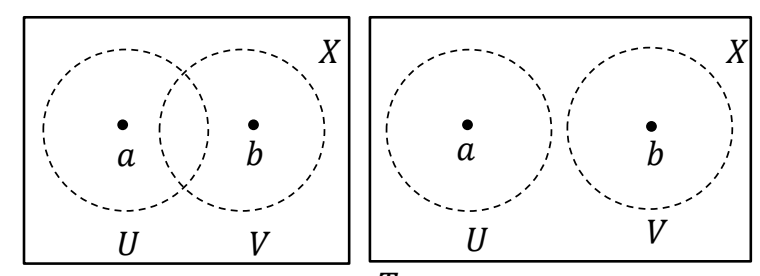

ruang- $T_{1}$
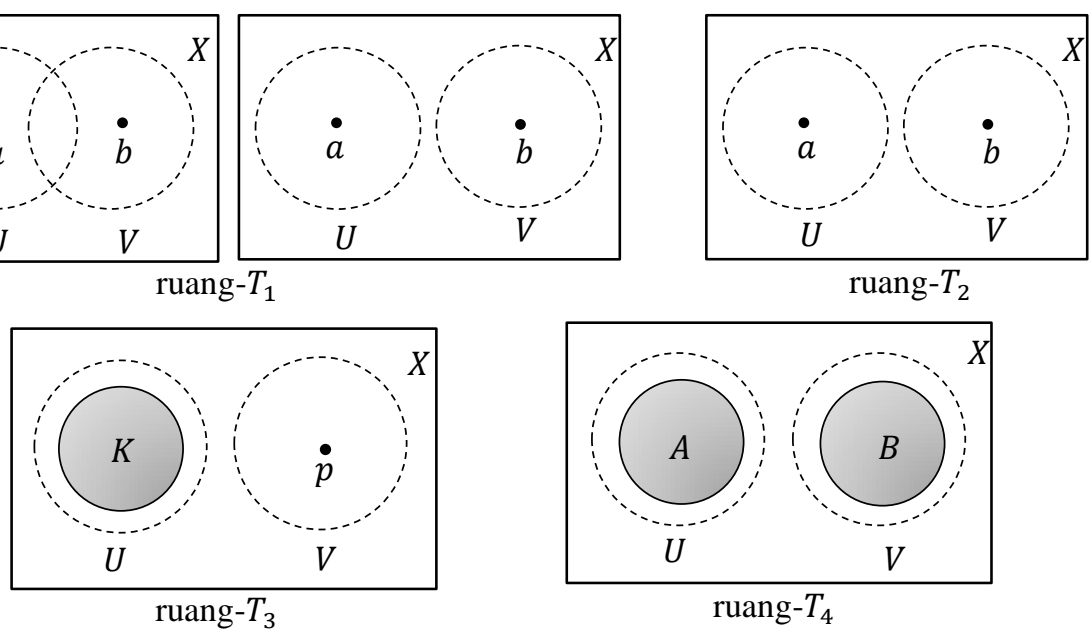

ruang- $T_{4}$

Gambar 1 Ilustrasi ruang pada aksioma pemisahan

Pada Definisi 1 terlihat bahwa ruang- $T_{3}$ dan ruang- $T_{4}$ belum tentu ruang- $T_{1}$. Selanjutnya jika ruang- $T_{3}$ dan ruang- $T_{4}$ secara berturut-turut merupakan ruang- $T_{1}$, maka ruang tersebut dikatakan sebagai ruang regular dan ruang normal. Berikut diberikan definisinya.

Definisi 2. [6] Misalkan $X$ merupakan ruang topologi

1. Ruang topologi $X$ dikatakan regular jika $X$ merupakan ruang Fréchet dan ruang- $T_{3}$.

2. Ruang topologi $X$ dikatakan normal jika $X$ merupakan ruang Fréchet dan ruang- $T_{4}$.

Contoh 1. Bilangan riil $\mathbb{R}$ dengan standar topologi merupakan ruang regular dan juga merupakan ruang normal sekaligus.

Setelah memahami mengenai ruang yang ada pada aksioma pemisahan, selanjutnya akan diberikan teorema yang membahas mengenai hubungan antara ruang pada aksioma pemisahan tersebut. 
Teorema 1. [6] Setiap ruang regular adalah ruang Hausdorff dan setiap ruang normal adalah ruang regular.

Bukti: (i) Pertama akan dibuktikan bahwa setiap ruang regular adalah ruang Hausdorff. Suatu ruang regular $X$ pastilah merupakan ruang Fréchet dan ruang- $T_{3}$, karenanya untuk setiap $p \in X$ maka singleton $\{p\}$ pastilah merupakan himpunan tertutup. Selanjutnya karena $X$ merupakan ruang- $T_{3}$ maka untuk setiap $q \in X$ dengan $q \neq p$ dan himpunan tertutup $\{p\} \subset X$ terdapat $U, V \subset X$ dengan $U \cap V=$ $\emptyset$ sedemikian hingga $\{p\} \subset U$ dan $q \in V$. Perhatikan bahwa $p \in\{p\} \subset U$, ini secara tidak langsung menyatakan bahwa $p \in U$. Dengan kata lain terlihat bahwa untuk sebarang $p, q \in X$ dengan $p \neq q$ terdapat himpunan saling asing $U, V \subset X$ sedemikian hingga $p \in U$ dan $q \in V$. Terbukti bahwa setiap ruang ruang regular adalah ruang Hausdorff. (ii) Selanjutnya akan dibuktikan bahwa setiap ruang normal adalah ruang regular. Misalkan $X$ adalah ruang normal maka $X$ pastilah ruang Fréchet sekaligus ruang- $T_{4}$. Karenanya untuk setiap $p \in X$ maka singleton $\{p\}$ pastilah merupakan himpunan tertutup. Selanjutnya ambil sebarang $K \subset X$ merupakan himpunan tertutup dengan $p \notin K$ maka $K \cap\{p\}=\varnothing$. Kemudian, karena $X$ merupakan ruang- $T_{4}$ maka untuk sebarang $K$ dan $\{p\}$ dengan $K \cap\{p\}=\emptyset$ terdapat himpunan terbuka saling asing $U, V \subset X$ sedemikian hingga $K \subset U$ dan $\{p\} \subset$ $V$. Perhatikan bahwa $p \in\{p\} \subset V$ maka $p \in V$ karenanya untuk sebarang $p \in V$ dan himpunan tertutup $K \subset X$ terdapat himpunan saling asing $U, V \subset X$ sedemikian hingga $K \subset U$ dan $\{p\} \subset V$. Secara tidak langsung ini menyatakan bahwa $X$ merupakan ruang- $T_{3}$. Karena $X$ merupakan ruang- $T_{3}$ dan juga ruang Fréchet maka $X$ merupakan ruang regular.

Berdasarkan (i) dan (ii) terbukti bahwa setiap ruang regular adalah ruang Hausdorff dan setiap ruang normal adalah ruang regular.

BerdasarkanTeorema 1 dapat diperoleh akibat sebagai berikut.

Akibat 2. Setiap ruang normal adalah ruang Hausdorff.

\section{KEKOMPAKAN}

Berikut diberikan definisi dari himpunan kompak pada ruang topologi.

Definisi 3. [2] Misalkan $A$ adalah himpunan bagian dari ruang topologi $X$, dan misalkan $\mathcal{O}=\left\{O_{\alpha} \mid \alpha \in I\right\}$ merupakan koleksi himpunan dari himpunan bagian $X$.

1. Koleksi $\mathcal{O}=\left\{O_{\alpha} \mid \alpha \in I\right\}$ disebut meliputi $A$ atau dikatakan liput $A$ jika $A$ termuat dalam gabungan himpunan $\mathcal{O}$ atau

$$
A \subseteq \bigcup_{\alpha \in I} O_{\alpha}
$$

2. Jika $\mathcal{O}$ liput $A$ dan untuk setiap himpunan di $\mathcal{O}$ terbuka, maka $\mathcal{O}$ disebut sebagai liput terbuka dari A.

3. Jika $\mathcal{O}$ liput $A$ dan $\mathcal{O}^{\prime}$ adalah koleksi bagian dari $\mathcal{O}$ yang juga meliputi $A$, maka $\mathcal{O}^{\prime}$ dikatakan sebagai liput bagian $\mathcal{O}$.

Contoh 2. [2] Diberikan koleksi dari interval $\mathcal{O}=\{\cdots,(-1,1),(0,2),(1,3), \cdots\}$ merupakan liput terbuka dari $\mathbb{R}$. Seperti yang dilihat dari koleksi tersebut, terlihat bahwa gabungan dari anggota $\mathcal{O}$ memuat $\mathbb{R}$. Namun banyak anggota $\mathcal{O}$ tidaklah berhingga.

Jika suatu liput terbuka memuat himpunan yang banyaknya tak hingga dapat direduksi menjadi koleksi bagian yang memuat himpunan yang banyaknya berhingga maka himpunan yang diliputi tersebut dikatakan kompak. Berikut diberikan definisi himpunan kompak. 
Definisi 4. [1] Sebuah ruang topologi $X$ dikatakan kompak jika untuk setiap liput terbuka $X$ yaitu $\mathcal{O}=\left\{O_{\alpha} \mid \alpha \in I\right\}$ terdapat liput bagian berhingga yaitu $\mathcal{O}^{\prime}=\left\{O^{\prime}{ }_{\beta} \mid \beta \in J\right\}$.

Contoh 3. [2] Misalkan $X=\left\{x_{1}, \cdots, x_{n}\right\}$ ruang topologi yang hanya memuat titik yang banyaknya berhingga. Karenanya hanya terdapat himpunan terbuka yang banyaknya berhingga pada topologi $X$. Himpunan terbuka anggota topologi $X$ ini merupakan liput terbuka himpunan $X$ karena topologi pada $X$ pastilah memuat minimal $\varnothing$ dan $X$ sehingga gabungan dari anggota topologi pastilah memuat himpunan $X$ itu sendiri. Dan karena anggota topologi banyaknya berhingga, maka $X$ kompak.

Berikut ini diberikan teorema mengenai sifat dari himpunan tertutup di ruang kompak.

Teorema 3. [7] Setiap himpunan tertutup $K$ di ruang kompak $X$ adalah kompak.

Bukti: Misalkan $\mathcal{A}=\left\{A_{\alpha} \mid \alpha \in I\right\}$ liput terbuka $K$ dari himpunan terbuka $X$. Diketahui $K$ tertutup maka $X-K$ terbuka. Misalkan $\mathcal{B}=\left\{B_{\beta} \mid \beta \in J\right\}$ liput terbuka $X-K$. Karenanya, anggota- anggota $\mathcal{A}$ bersama dengan $\mathcal{B}$ membentuk sebuah liput terbuka dari $X$.

$$
X \subset\left(\left(\bigcup_{\alpha \in I} A_{\alpha}\right) \cup\left(\bigcup_{\beta \in J} B_{\beta}\right)\right) .
$$

Diketahui $X$ kompak, maka liput terbuka $X$ memuat liput bagian berhingga dari $X$. Berdasarkan definisi liput bagian, dapat diketahui bahwa liput juga merupakan liput bagian. Karena $X$ kompak maka liput dari $X$ berhingga. Dengan kata lain, $\mathcal{A}, \mathcal{B}$ berhingga. Karena $\mathcal{A}$ berhingga dan juga merupakan liput bagian, maka $K$ kompak.

\section{RUANG HAUSDORFF KOMPAK}

Suatu ruang Hausdorff yang memenuhi sifat kekompakan maka ruang tersebut disebut sebagai ruang Hausdorff kompak. Berikut akan diberikan teorema yang terkait dengan ruang Hausdorff kompak.

Teorema 4. [6] Misalkan $X$ merupakan ruang Hausdorff.

1. Jika $K \subseteq X$ kompak dan $p \in X-K$, maka terdapat himpunan terbuka $U, V \subseteq X$ dengan $U \cap V=\emptyset$ sedemikian hingga $K \subset U$ dan $p \in V$

2. Setiap himpunan bagian kompak $K \subseteq X$ tertutup.

3. Jika $X$ kompak maka $X$ merupakan ruang regular.

Bukti: 1 . Misalkan $a \in K$, karena $p \notin K, p \neq a$ dan $X$ ruang Hausdorff maka berdasarkan definisi ruang Hausdorff terdapat himpunan terbuka saling asing $U_{a}$ dan $V_{a}$ dari $X$ sedemikian hingga $a \in U_{a}$ dan $p \in V_{a}$. Oleh karena itu $K \subset \mathcal{F}=\left\{U_{a} \mid a \in K\right\}$ dimana $\mathcal{F}$ adalah liput terbuka dari $K$. Diketahui $K$ kompak maka $\mathcal{F}$ memiliki liput bagian berhingga dari $K$. Dengan kata lain, terdapat bilangan berhingga yaitu $a_{1}, \cdots, a_{n} \in K$ sedemikian hingga $K$ termuat dalam gabungan

Di lain sisi, misalkan

$$
U=U_{a_{1}} \cup \cdots \cup U_{a_{n}} .
$$

$$
V=V_{a_{1}} \cap \cdots \cap V_{a_{n}}
$$

Maka $U$ dan $V$ merupakan himpunan terbuka dari $X$ sedemikian hingga $K \subset U$ dan $p \in V$. Selanjutnya akan ditunjukkan $U$ dan $V$ saling asing. Diketahui $U_{a_{i}} \cap V_{a_{i}}=\emptyset$. Secara tidak langsung ini menyatakan $U_{a_{i}} \cap V=\varnothing$. Berdasarkan hukum distributif maka

$$
\begin{aligned}
U \cap V & =\left(U_{a_{1}} \cup \cdots \cup U_{a_{n}}\right) \cap V \\
& =\left(U_{a_{1}} \cap V\right) \cup \cdots \cup\left(U_{a_{n}} \cap V\right) \\
& =\emptyset \cup \cdots \cup \emptyset=\emptyset .
\end{aligned}
$$


Terbukti bahwa $K \subset U, p \in V$ dan $U \cap V=\emptyset$.

2. Diketahui $K$ himpunan kompak dari ruang Hausdorff $X$ maka berdasarkan Teorema 4 poin 1 , terdapat himpunan terbuka $U$ dan $V$ di $X$ sedemikian hingga $K \subset U, p \in V$ dan $U \cap V=\emptyset$. Karenanya $K \cap V=\varnothing$ dan $p \in V \subset(X-K)$. Selanjutnya akan ditunjukkan bahwa $X-K$ terbuka. Karena $p \in V \subset(X-K)$ maka $(X-K)=\bigcup\left\{V_{p} \mid p \in X-K\right\}$. Diketahui $V_{p}$ himpunan terbuka maka $X-K$ merupakan himpunan terbuka. Dengan kata lain $K$ himpunan tertutup.

3. Diketahui $X$ kompak, maka berdasarkan Teorema 4 poin 2 setiap himpunan bagian $K \subseteq X$ tertutup. Selanjutnya karena $K \subseteq X$ tertutup dan kompak, maka berdasarkan Teorema 4 poin 1 untuk setiap $p \in X-K$ terdapat himpunan terbuka $U, V \subseteq X$ dengan $U \cap V=\emptyset$ sedemikian hingga $K \subset U$ dan $p \in V$. Dengan kata lain $X$ merupakan ruang- $T_{3}$. Lebih lanjut karena $X$ adalah ruang Hausdorff maka $X$ juga merupakan ruang Fréchet. Dengan demikian dapat disimpulkan bahwa $X$ merupakan ruang regular.

Teorema 3 menyatakan bahwa setiap himpunan tertutup $K$ di ruang kompak $X$ adalah kompak, namun belum tentu sebaliknya. Selanjutnya berdasarkan Teorema 4 poin 2 menyatakan bahwa setiap himpunan bagian kompak $K$ di ruang Hausdorff adalah tertutup. Berdasarkan kedua teorema ini diperoleh akibat sebagai berikut.

Akibat 5. [6]. Suatu himpunan bagian $K \subseteq \mathbb{R}$ dikatakan kompak jika dan hanya jika $K$ tertutup dan terbatas.

Bukti: $(\Rightarrow)$ Diketahui $K \subseteq \mathbb{R}$ kompak dan misalkan himpunan $(-n, n)$ dengan $n \in \mathbb{N}$ merupakan liput terbuka dari $\mathbb{R}$. Maka himpunan bagian $K$ pastilah termuat dalam salah satu himpunan $(-n, n)$ dengan $n \in \mathbb{N}$ tersebut. Dengan kata lain $K$ memiliki batas atas dan batas bawah, sehingga $K$ terbatas. Selanjutnya, berdasarkan Teorema 4 poin 2 maka $K$ tertutup. Oleh karena itu, terbukti bahwa $K$ tertutup dan terbatas.

$(\Leftarrow)$ Diketahui $K$ tertutup dan terbatas maka berdasarkan Teorema $3 K$ kompak.

Selanjutnya akan diberikan teorema yang menyatakan bahwa suatu ruang Hausdorff kompak merupakan ruang normal.

Teorema 6. [6] Misalkan $X$ ruang Hausodrff kompak maka $X$ normal.

Bukti: Diketahui $X$ ruang Hausdorff kompak. Akan ditunjukkan $X$ ruang normal. Untuk menunjukkan $X$ normal, terlebih dahulu akan ditunjukkan bahwa $X$ merupakan ruang- $T_{4}$. Diberikan himpunan tertutup $A, B \subseteq X$, maka berdasarkan Teorema 3, $A$ dan $B$ keduanya kompak. Selanjutnya misalkan $a \in A$ maka $a \notin B$, untuk $A$ dan $B$ saling asing. Berdasarkan hipotesis, $B$ kompak karenanya berdasarkan Teorema 3 poin 1 terdapat himpunan terbuka $U_{a}$ dan $V_{a}$ sedemikian hingga

$$
a \in U_{a}, B \subset V_{a} \text { dan } U_{a} \cap V_{a}=\varnothing \text {. }
$$

Karena $a \in U_{a}$ maka $\mathcal{F}=\left\{U_{a} \mid a \in A\right\}$ adalah liput terbuka dari $A$. Diketahui $A$ kompak, maka $\mathcal{F}$ memiliki liput berhingga dari himpunan terbuka. Dengan kata lain, terdapat bilangan berhingga yaitu titik $a_{1}, \cdots, a_{n} \in A$ sedemikian hingga

$$
A \subset U_{a_{1}} \cup \cdots \cup U_{a_{m}}
$$

Selanjutnya, karena $B$ adalah himpunan bagian dari masing-masing $V_{a_{i}}$ maka

$$
B \subset V_{a_{1}} \cap \cdots \cap V_{a_{m}} .
$$

Sekarang misalkan $U=U_{a_{1}} \cup \cdots \cup U_{a_{m}}$ dan $V=V_{a_{1}} \cap \cdots \cap V_{a_{m}}$. Maka berdasarkan penjabaran diatas diperoleh $A \subset U$ dan $B \subset V$. Karena $U$ dan $V$ secara berturut-turut adalah gabungan dan irisan terbatas dari himpunan terbuka maka $U$ dan $V$ adalah himpunan terbuka. Selanjutnya akan ditunjukkan $U$ dan 
$V$ saling asing. Perhatikan bahwa, untuk setiap $i, U_{a_{i}} \cap V_{a_{i}}=\emptyset$ secara tidak langsung ini menunjukkan $U_{a_{i}} \cap V=\emptyset$. Karenanya, berdasarkan hukum distribusi

$$
\begin{aligned}
U \cap V & =\left(U_{a_{1}}, \cdots, U_{a_{m}}\right) \cap V \\
& =\left(U_{a_{1}} \cap V\right) \cup \cdots \cup\left(U_{a_{m}} \cap V\right) \\
& =\emptyset \cup \cdots \cup \emptyset \\
& =\emptyset .
\end{aligned}
$$

Dengan demikian karena $A \subset U, B \subset V$ dan $U \cap V=\varnothing$ maka terbukti bahwa $X$ merupakan ruang- $T_{4}$. Dari pernyataan awal diketahui $X$ ruang Hausdorff, maka $X$ juga merupakan ruang Fréchet. Karena $X$ ruang Fréchet dan juga merupakan ruang- $T_{4}$, maka $X$ merupakan ruang normal.

\section{PENUTUP}

Berdasarkan analisis dan pembahasan yang telah dijabarkan, dapat disimpulkan bahwa suatu ruang normal pastilah ruang regular dan ruang regular pastilah ruang Hausdorff. Jika dikaitkan maka didapat hubungan bahwa suatu ruang normal pastilah ruang regular dan karena ruang regular merupakan ruang Hausdorff maka ruang normal juga merupakan ruang Hausdorff. Namun ruang Hausodrff belum tentu merupakan ruang normal dan ruang regular. Akan tetapi jika suatu ruang Hausdorff yang dilengkapi dengan sifat kekompakan maka ruang Hausdorff kompak ini merupakan ruang normal dan pastilah juga merupakan ruang regular. Selanjutnya apabila $X$ ruang Hausdorff kompak maka suatu himpunan $K \subseteq X$ dikatakan kompak jika dan hanya jika $K$ tertutup dan terbatas.

\section{DAFTAR PUSTAKA}

[1] Mendelson B. Introduction to Topology. United States of America: Allyn and Bacon; 1962.

[2] Adams C, Franzosa R. Introduction to Topology: Pure and Applied. India: Dorling Kindersley; 2009.

[3] Lipschutz S. Schaum's Outline of Theory and Problems of General Topology. United States of America: McGraw Hill; 1965.

[4] Soewongsono AC et al. Teorema Berbasis Aksioma Separasi dalam Ruang Topologi. Jurnal Matematika Integratif. 2015; 11:85-96.

[5] Wallace AH. An Introction to Algebraic Topology. Northern Ireland: Dover Publications; 2007.

[6] Waldmann S. Topology An Introduction. Switzerland: Springer International Publishing; 2014.

[7] Munkres J. Topology Second Edition. United States of America: Prentice Hall; 2000.

PUTRI APRILLA SURI: FMIPA UNTAN Pontianak, cillaput04@gmail.com

MARIATUL KIFTIAH : FMIPA UNTAN Pontianak, kiftiahmariatul@ math.untan.ac.id

YUNDARI : FMIPA UNTAN Pontianak, yundari@math.untan.ac.id 